\title{
LA TELEDETECCIÓN COMO HERRAMIENTA DE ANÁLISIS DEL CRECIMIENTO URBANO Y SU REPRESENTACIÓN EN 3D
}

\author{
Luis Ángel Ruiz Fernández, Amelia del Rey Pérez, Javier Estornell \\ Cremades, Rafael Ruiz Marín
}

Departamento de Ingeniería Cartográfica, Geodesia y Fotogrametría. Universidad Politécnica de Valencia. Camino de Vera s/n. 46022 Valencia. (laruiz@cgf.upv.es)

Departamento de Teledetección y SIG. INICIAS, Dirección y Gestión de Iniciativas, S.A. C/ Avellanas, 14-1º, 46003 Valencia. (dt3@inicias.com)

Remisión Artículo: 2-5-2007

Palabras clave: teledetección, crecimiento urbano, 3D, ortoimagen.

Resumen. En este trabajo se presenta un caso práctico de aplicación de técnicas de procesado digital de imágenes de satélite para la identificación de cambios en el área metropolitana de Valencia, y su representación en un entorno 3D obtenido a partir de la integración de imágenes de alta resolución y de un MDE. Para ello, se describen algunos procedimientos de detección automática de cambios que incluyen el preprocesado radiométrico y la georreferenciación de las imágenes, obteniendo un mapa de cambios relativo al crecimiento urbano entre dos fechas. A continuación, se describe el procedimiento seguido para la ortorrectificación y realce de una imagen de alta resolución (QuickBird), donde se fusiona la imagen pancromática con la multiespectral. Por último, utilizando como base los resultados anteriores, se genera un vuelo interactivo 3D del terreno en el que aparecen destacados los principales cambios en el entorno urbano de Valencia, relacionados con la correspondiente base de datos SIG.

\section{Introducción}

La diversidad de imágenes obtenidas desde plataformas satelitales nos permite analizar el territorio desde una perspectiva cada vez más completa. La variedad de resoluciones espaciales hace posible estudios a diferentes escalas, mientras que la información espectral posibilita la caracterización de espacios o unidades de paisaje. Todo ello, unido a la periodicidad de adquisición de las imágenes, hace que estas técnicas sean idóneas para seguir la evolución del territorio a lo largo del tiempo. Por otra parte, el alto ritmo de desarrollo urbanístico actual de las ciudades crea la necesidad de poner a punto técnicas y métodos para la actualización cartográfica de estos entornos tan dinámicos.

Existen numerosos estudios sobre la aplicación de las técnicas de teledetección para la detección de cambios, por ejemplo a partir del cálculo de índices de vegetación y ratios entre las bandas 5 y 7 de imágenes Landsat (Howarth y Boasson 1983), o el análisis del desarrollo urbano utilizando clasificaciones supervisadas mediante imágenes SPOT (Martin y Howarth 1989). Por su parte, Ridd y Liu (1998) evaluaron cuatro métodos para la detección de cambios de naturaleza urbana: diferencia entre bandas, imagen regresión, transformación tasseled cap y transformación. En otras ocasiones, la utilización de ciertos métodos como el basado en 
el vector de cambios, por ejemplo, produce buenos resultados en la localización de cambios urbanos (Sohl 1999). Un aspecto común en todos ellos es la necesidad de aplicar procesos de normalización radiométrica a las imágenes originales para poder valorar los cambios del paisaje que tengan lugar como consecuencia de las diferencias en la reflectancia de las superficies, y no como resultado de las diferencias en la calibración de los sensores, o de la diversidad atmosférica entre las fechas de adquisición de las imágenes (Xiaojun y Lo, 2000).

En este trabajo se propone una metodología basada en técnicas de tratamiento digital de imágenes para la detección de cambios en áreas urbanas y su aplicación en la zona metropolitana de Valencia, incluyendo un procedimiento exhaustivo de evaluación y selección de un método de normalización radiométrica de las imágenes. Se describe el proceso para la generación, realce y edición de una ortoimagen digital a partir de una imagen espacial de alta resolución (QuickBird). Por último, se ha realizado un vuelo virtual en 3D a partir de la ortoimagen espacial, incluyendo la información sobre cambios urbanos obtenida. La aplicación completa muestra las posibilidades que ofrece la integración de las técnicas cartográficas y de análisis en la visualización e interpretación de los cambios y en la gestión de la evolución de zonas urbanas.

\section{Zona de estudio y datos}

La zona de estudio se corresponde con el área metropolitana de Valencia, ciudad que ha experimentado un fuerte crecimiento urbano en los últimos años. El área queda acotada por las

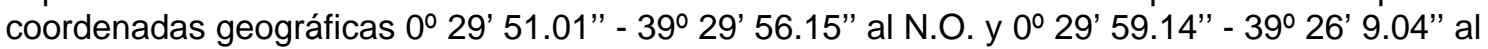
S.E.

\section{Imágenes}

En el análisis de cambios se emplearon dos imágenes de resolución media, adquiridas por el sensor LISS-III, a bordo de los satélites IRS 1C y 1D, en junio de 1996 y en septiembre de 1999 (figura 1). Además, con objeto de evaluar y contrastar diversos métodos empleados en este estudio se usaron otras dos imágenes, una pancromática del satélite IRS-1C, adquirida en septiembre de 1996, y una imagen IKONOS de mayor resolución espacial tomada el 23 de diciembre del 2000.

Para la generación de la ortoimagen espacial se utilizaron dos imágenes, una pancromática y otra multiespectral, adquiridas en febrero de 2004 por el satélite QuickBird, de órbita heliosíncrona situada a una altitud de unos $450 \mathrm{~km}$. La imagen pancromática tiene una resolución espacial de 0,61 m/píxel (nadir) y un intervalo espectral entre 450-900 nm., mientras que la resolución de la imagen multiespectral es de 2,44 metros (nadir) y posee 4 bandas espectrales: azul $(450-520 \mathrm{~nm})$, verde $(520-600 \mathrm{~nm})$, roja $(630-690 \mathrm{~nm})$ e infrarroja cercana (760-900 nm). La resolución radiométrica de ambas es de 11 bits por píxel. 


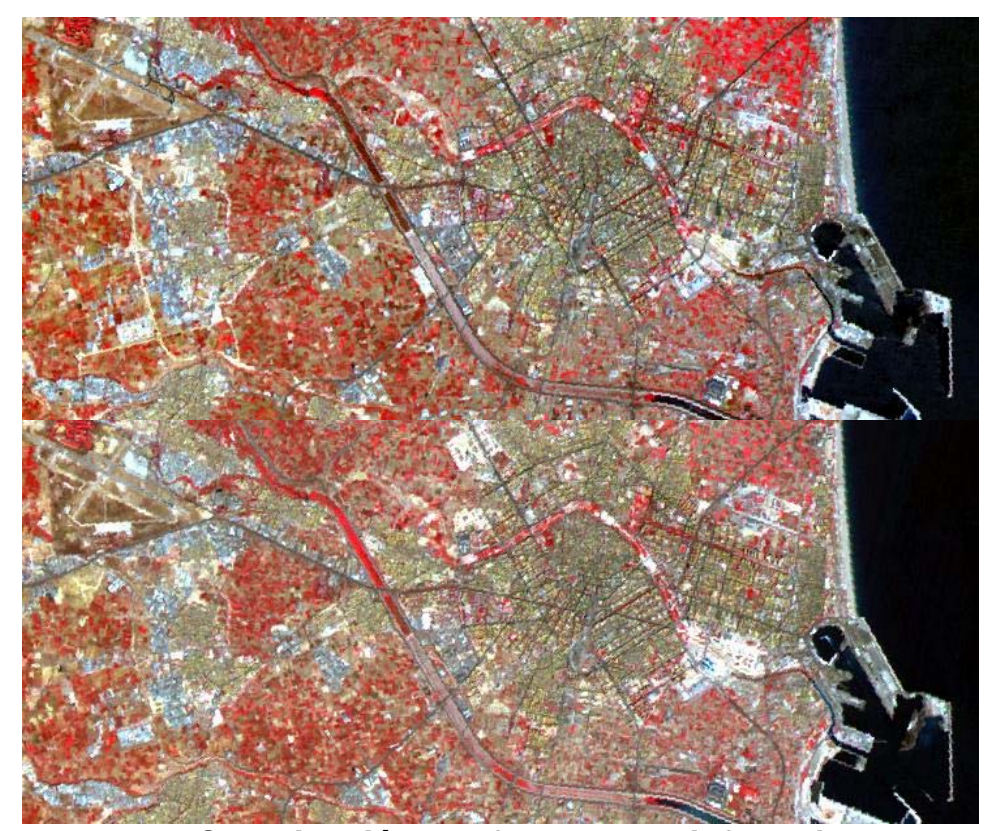

Figura 1.- Combinación en falso color infrarrojo de las imágenes IRS utilizadas en el análisis de cambios: Junio de 1996 (arriba) y septiembre de 1999 (abajo).

\section{Cartografía y MDT}

Los procesos de corrección geométrica de las imágenes de resolución media (IRS) se realizaron con la base cartográfica de escala 1:10.000 del Instituto Cartográfico Valenciano. La cartografía base utilizada para la ortorrectificación de la imagen QuickBird de alta resolución fue fundamentalmente la cartografía catastral urbana, que abarca la totalidad del casco urbano de cada municipio, y la cartografía municipal. Sus escalas oscilan entre 1:500 y 1:2.000.

Se emplearon dos MDT, uno de ellos con un paso de malla de 10 metros obtenido a partir de la cartografía a escala 1:10.000 mencionada, y otro con paso de malla de 25 metros, este último se usó en la realización del vuelo 3D.

\section{Software}

Se emplearon los programas ENVI versión 3.2 y ERDAS versión 8.5 de tratamiento digital de imágenes y los programas ArcView 3.2, ArcGis 8.1 y AutoCad 2000 para la generación de cartografía y maquetación. La programación de los algoritmos de normalización radiométrica se llevó a cabo en el entorno IDL. La personalización de los métodos de detección de cambios, fusión y la corrección de saturaciones en la imagen QuickBird se programó mediante el módulo Modeler de Erdas. Por último, el vuelo interactivo se generó mediante el paquete de software TerraSuit, de Skyline Software System Ltd., el cual está compuesto por tres módulos: Terra Explorer Pro, Terra Builder y Terra Developer.

\section{Metodología de identificación de cambios en el entorno urbano}

En los procesos de identificación de cambios mediante el procesado de imágenes de satélite pueden diferenciarse dos fases: (1) Las operaciones de preprocesado geométrico y radiométrico, cuyo objeto es preparar las imágenes iniciales para que puedan ser analizadas; y (2) la aplicación y comparación de los métodos de extracción automática de cambios y la posterior selección del más apropiado, el cual se usará para obtener la cartografía final de nuevas áreas urbanas. En la figura 2 se muestra un esquema del procedimiento global seguido y en los siguientes subapartados se describe cada una de estas fases. 


\section{Operaciones de preprocesado}

\section{Correcciones geométricas}

Consisten en la georreferenciación y registro geométrico de las imágenes, de forma que se reduzcan los errores generados durante la adquisición, se les asignen coordenadas cartográficas y se minimicen las diferencias de posición relativas, permitiendo así su comparación píxel a píxel.

En primer lugar se rectificó la imagen IRS de junio de 1996 tomando como referencia la cartografía base a escala 1:10.000 (en proyección UTM con elipsoide de referencia 1909 y datum europeo de 1950). La transformación geométrica se obtuvo mediante ajuste polinomial de segundo grado, tomando 24 puntos de control distribuidos de forma regular, obteniendo un error medio cuadrático de 0,40 píxeles. Como método de remuestreo se empleó el del vecino más próximo, por preservar mejor los valores radiométricos de las imágenes originales. Posteriormente, se registró la imagen de 1999 con respecto a la anterior, empleando parámetros análogos, obteniendo un error cuadrático medio de 0,35 píxeles, lo que asegura una buena correspondencia geométrica entre ambas imágenes, factor importante para las aplicaciones de análisis de cambios.

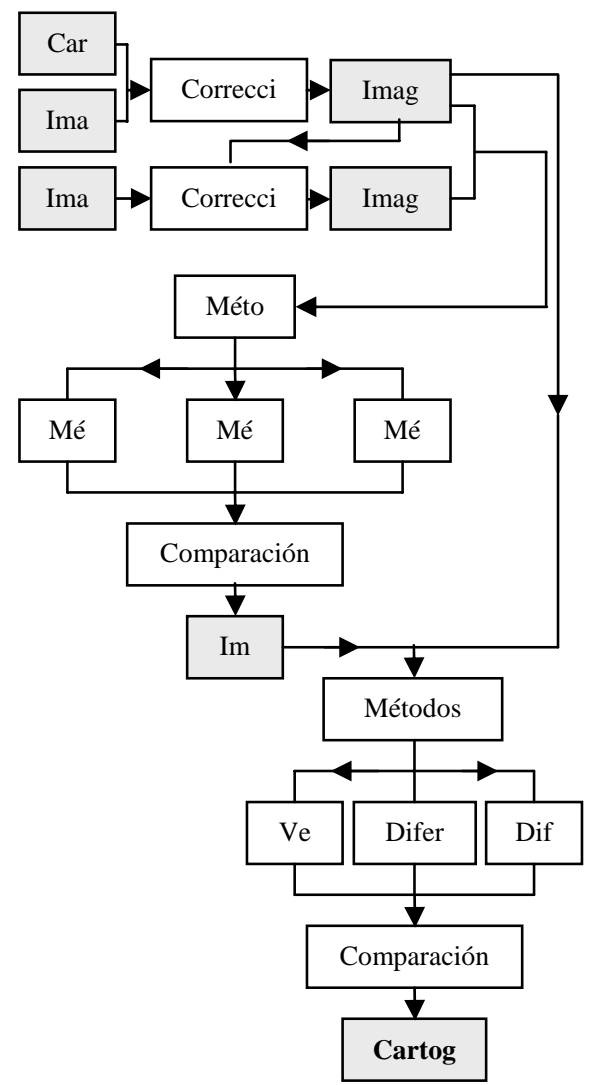

Figura 2.-. Esquema metodológico seguido en el proceso de identificación de cambios. Correcciones radiométricas

Su objeto es el de reducir las diferencias radiométricas entre imágenes que son debidas a las distintas condiciones atmosféricas y de calibración del sensor en las dos fechas consideradas. Para ello, se aplicaron y evaluaron varios métodos de normalización radiométrica, seleccionando el más idóneo para este caso. La normalización radiométrica relativa compara 
los niveles de intensidad de las imágenes objeto y de referencia, estableciendo relaciones entre ellas y aplicando una transformación radiométrica sobre la primera. Se tomó como imagen objeto de normalización la de septiembre de 1999 y como referencia la de junio de 1996. Estos métodos tienen la ventaja de no necesitar datos atmosféricos para su aplicación. Siguiendo el trabajo de Mateu y Ruiz (1999), se evaluaron 3 tipos de métodos: globales, adaptativos y específicos.

Los métodos globales utilizan toda la imagen para realizar la normalización radiométrica, con la desventaja de que pueden eliminar parte del cambio que se desea estudiar, y su efecto varía en función de las variaciones de la zona de estudio en cuestión. Entre los métodos de normalización globales se pueden citar los siguientes: Mínimo-máximo, media-desviación estándar y regresión simple. Así, por ejemplo, el método de mínimo-máximo consiste en el cálculo y aplicación de una transformación lineal, $y=a x+b$, sobre el histograma original, donde los coeficientes "a" $y$ " $b$ " se obtienen de la siguiente manera:

$\mathrm{a}=\left(\right.$ ndmax $_{\text {IMAGEN REFERENCIA }}$ - ndmin IMAGEN REFERENCIA $) /\left(\right.$ ndmax $_{\text {IMAGEN OJBETO }}$ - ndmin IMAGEN OBJETO $)$

$\mathrm{b}=$ ndmin $_{\text {IMAGEN REFERENCIA-a*ndmin }}$ IMAGEN OBJETO

Los métodos adaptativos consisten en dividir la imagen en varias regiones o ventanas con un vecindario determinado. Para cada una de estas regiones se calculan los valores de normalización que se aplicarán a la imagen objeto. Dentro de los métodos adaptativos se encuentra el adaptativo bilineal. Por cada ventana, se calculan los valores de la media y la desviación típica en la imagen de referencia y en la imagen objeto. A partir de estos parámetros se obtienen los valores de los coeficientes "a" y " $b$ " del ajuste lineal $y=a x+b$. La normalización final de la imagen se establece mediante la interpolación bilineal de los coeficientes más cercanos a cada píxel.

Los métodos específicos son aquellos que utilizan únicamente muestras que no presentan cambios en las imágenes que se van a comparar. La normalización se realiza mediante una transformación lineal del tipo $y=a x+b$, donde " $y$ " representa el valor de los píxeles de la imagen modificada, " $x$ " el de los píxeles de la imagen original, mientras que "a" $y$ " $b$ " son los coeficientes que se precisa calcular. Para su cálculo, dos de los métodos que pueden usarse son el basado en la media y desviación típica y el de regresión simple.

La comparación de los distintos métodos de normalización se llevó a cabo mediante 3 índices: El error medio cuadrático (EMC), el rango dinámico de los niveles de intensidad y su coeficiente de variación. El EMC se utiliza como medida estadística de la calidad de la normalización (Yuan y Elvidge, 1996), y se define mediante la expresión:

$E M C_{i}=\frac{1}{\mid \text { Muestra }_{i} \mid} \Sigma\left(x_{k}-y_{k}\right)^{2}$

donde $x_{k}$ representa los valores radiométricos de la imagen normalizada (modificada) y $y_{k}$ los de la imagen de referencia. Muestra representa el número de total de píxeles incluidos en el análisis, coincidiendo con el número total de píxeles de la imagen en los métodos globales, y con el número de píxeles tomados en la muestra en el caso de los métodos específicos. Cuanto menor sea el EMC mayor es la semejanza entre las imágenes.

La normalización radiométrica modifica los valores radiométricos de las imágenes, alterando el contraste y las covarianzas entre bandas espectrales, lo que puede afectar al resultado de la clasificación de la imagen e incluso a la detección de los tipos de cambios. El rango dinámico y el coeficiente de variación de los niveles de intensidad obtenidos en cada caso permiten 
cuantificar esta modificación (Xiaojun y Lo, 2000). Una descripción más detallada de los métodos de normalización y de los parámetros empleados para su evaluación puede encontrarse en trabajos anteriores (Mateu y Ruiz, 1999; Estornell et al., 2004).

Considerando estos parámetros estadísticos, el método con el que se obtuvieron mejores resultados fue el específico de media y desviación estándar con selección de muestras invariantes. Hay que destacar también los buenos resultados estadísticos del método de normalización global de media y desviación estándar. Sin embargo, el método de normalización adaptativo bilineal, si bien resulta útil en otras aplicaciones, en nuestro caso introduce errores importantes, eliminando los cambios reales que se quieren detectar. La figura 3 muestra un ejemplo de este efecto, donde la zona remarcada sobre la imagen normalizada del año 1999 aparece con un aspecto similar al de 1996, aunque no debería ocurrir ya que se trata de una zona de cambio real entre ambas fechas.

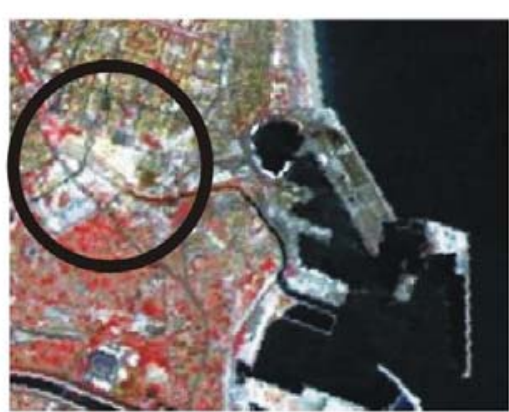

IMAGEN JUNIO 1996

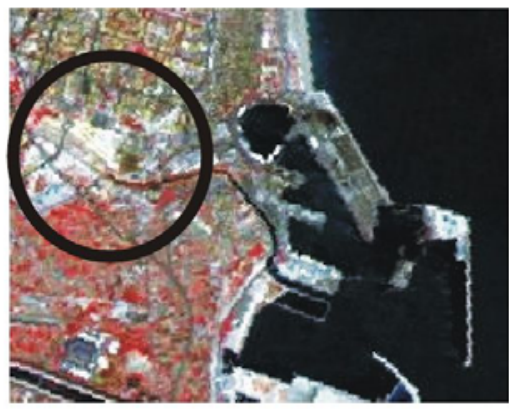

IMAGEN NORMALIZADA MÉTODO ADAPTATIVO BILINEAL

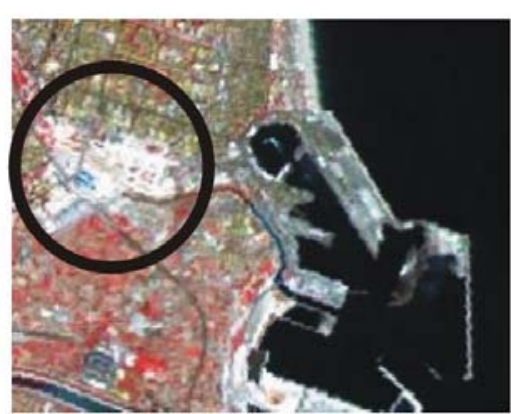

IMAGEN SEPTIEMBRE 1999

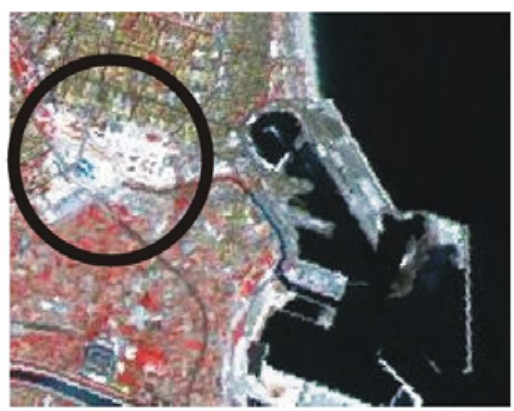

IMAGEN NORMALIZADA MÉTODO $\mu, \sigma$ CON SELECCIÓN DE MUESTRAS INVARIANTES

Figura 3.- Detalles de la imagen de referencia de junio de 1996 y de la imagen de septiembre de 1999 antes de su normalización (arriba); y los resultados de esta última tras aplicar los métodos de normalización adaptativo bilineal y media-desviación típica con selección de muestras invariantes (abajo). Puede apreciarse cómo en la imagen normalizada por el método adaptativo bilineal desaparece una zona de cambio real.

\section{Detección automática de cambios}

Existe una gran variedad de métodos para la identificación de cambios a partir de imágenes multiespectrales y multitemporales. En este trabajo se aplicaron y evaluaron tres de ellos: (1) vector de cambios, (2) comparación postclasificación, y (3) método mixto diferenciaclasificación. A continuación se describe cada uno de ellos. 
Método del vector de cambios

El método del vector de cambios consiste en el cálculo del módulo y la dirección del vector que une los valores de los píxeles, en el espacio definido por dos bandas espectrales, en dos fechas diferentes. En nuestro caso se utilizaron dos bandas del sensor LISS-III, la banda del rojo (b2) e infrarrojo cercano (b3), de las dos imágenes ajustadas tanto geométrica como radiométricamente. El módulo hace referencia a la magnitud o importancia del cambio. Un módulo alto supone un cambio significativo. La dirección se refiere al tipo de cambio. El módulo y la dirección se obtienen aplicando píxel a píxel las expresiones:

$$
\begin{aligned}
& \Delta x=i m 99_{b 2}-i m 96_{b 2} \\
& \Delta y=i m 99_{b 3}-i m 96_{b 3} \\
& \text { módulo }=\sqrt{\Delta x^{2}+\Delta y^{2}} \\
& \text { dirección }=\arctan \frac{\Delta x}{\Delta y}
\end{aligned}
$$

donde $i m 99_{b 2}$, por ejemplo, representa el valor de intensidad de cada píxel de la banda 2 en la imagen de 1999.

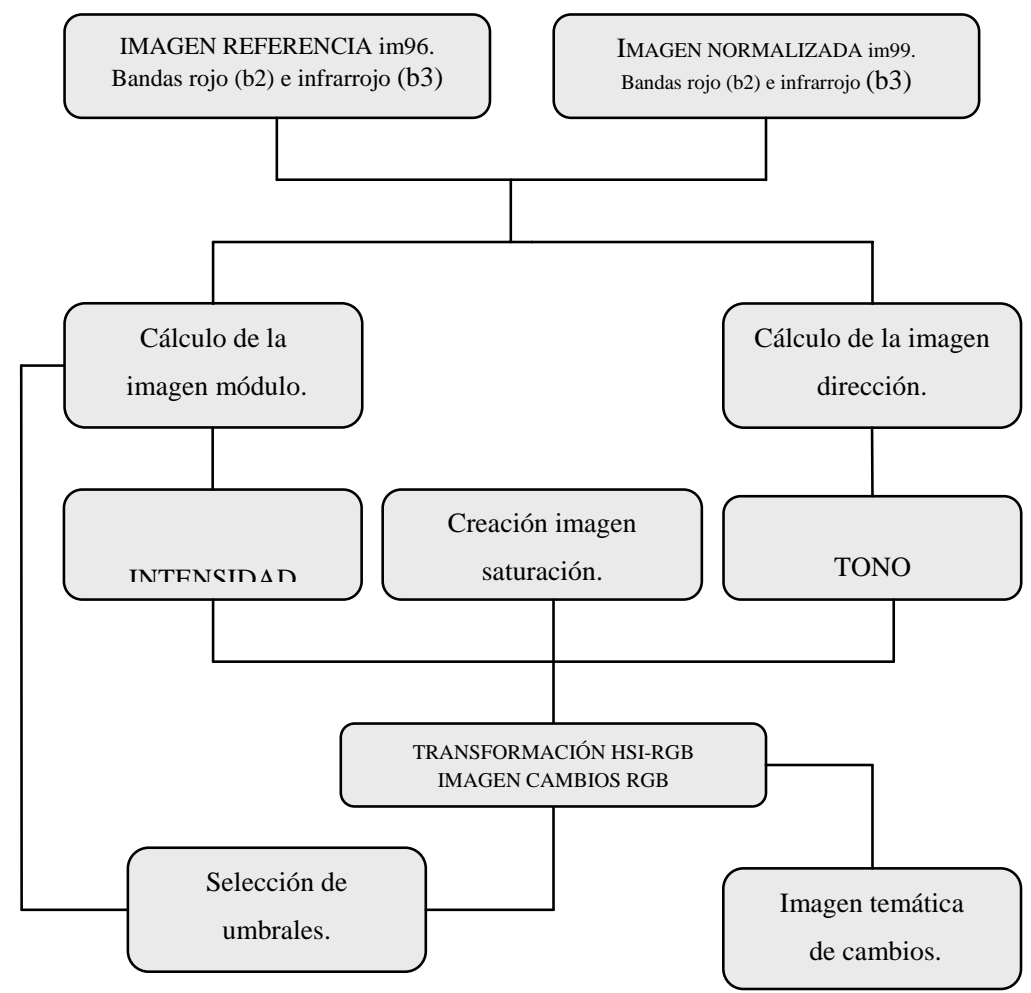

Figura 4.- Esquema del método del vector de cambios.

A partir de las componentes del vector se puede formar una imagen en el espacio de color HSI, en la que al valor de intensidad (I) se le hace corresponder el módulo del vector de cambios reescalado linealmente a valores comprendidos entre 0 y 1 . El tono $(\mathrm{H})$ equivale a la componente dirección, transformando el valor del arco tangente a valores de grados sexagesimales, entre $0^{\circ}$ y $360^{\circ}$. A la saturación (S) se le asigna un valor constante de 1 . Una vez obtenida esta imagen, su transformación al espacio del color RGB facilita la interpretación 
de los cambios entre ambas fechas. La figura 4 recoge el procedimiento completo de este método.

Se obtuvo de esta manera una imagen de cambios, donde el nivel de brillo o intensidad está relacionado con la magnitud del cambio y cada tono representa un tipo de cambio.

A grandes rasgos, los tonos magenta y blancos indican cambios de suelo no urbanizado a urbanizado, los azules representan una transición desde zonas con mayor presencia de vegetación a zonas con menos vegetación, los amarillos indican un cambio de áreas con menor presencia de vegetación a zonas con mayor presencia y las superficies con tonalidades verdosas representan un descenso de la reflectancia de ciertas coberturas en el periodo analizado (figura 5).

Suponiendo que los valores correspondientes a cambios reales se sitúan en los extremos del histograma de frecuencias de la imagen del módulo, se consideraron zonas de cambio las regiones del histograma de la imagen del módulo cuyo valor superara un cierto valor umbral en ambos extremos. Tras un estudio del mismo, este valor se tomó a partir de $2 \sigma$ con respecto del valor medio del histograma. Así, en la figura 6 , los grises corresponden a zonas en las que no se han producido variaciones $(<\mu-2 \sigma$ ó $>\mu+2 \sigma)$, y los diferentes tonos representan los tipos de cambio descritos.

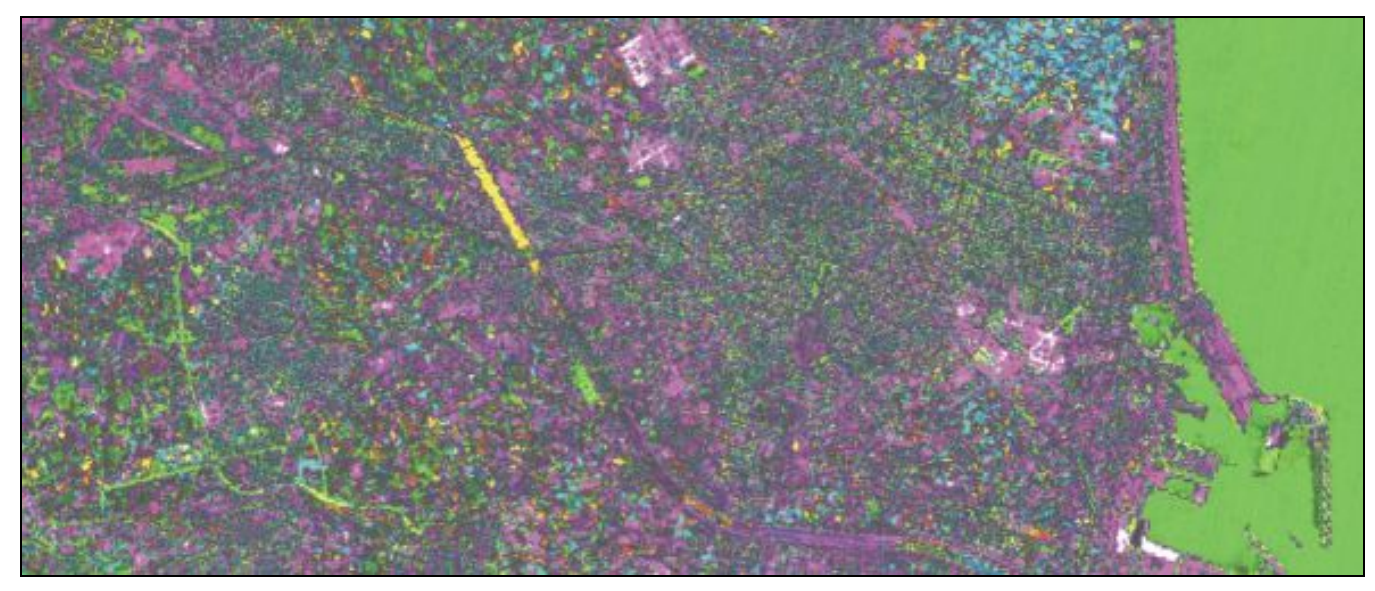

Nuevas zonas urbanas

Descenso de reflectividad

Aumento de vegetación

Descenso vegetación

Figura 5.- Imagen resultado de aplicar el método del vector de cambios. 


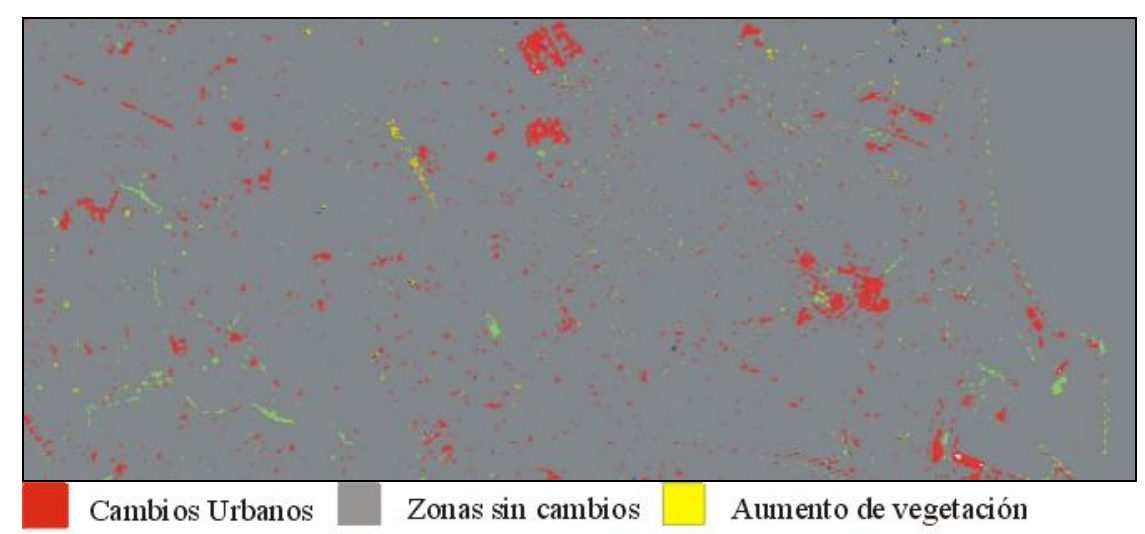

Descenso de reflectividad asociado a la terminación de construcciones.

Figura 6. Resultado del método del vector de cambios, enmascarando los valores comprendidos entre $\pm 2 \sigma$ a partir del valor medio del histograma del módulo.

Método de comparación postclasificación

Este método consiste en comparar dos clasificaciones supervisadas obtenidas a partir de imágenes de distintas fechas. El primer paso a la hora de abordar una clasificación es la definición de las clases que se quieren discriminar. Para el presente estudio se consideraron las siguientes: suelo no urbanizado, suelo uso industrial, infraestructuras-carreteras, suelo residencial-ciudad y agua. Por otra parte, como datos de entrada se emplearon las siguientes bandas:

- Bandas espectrales del sensor LISS-III correspondientes al verde, rojo e infrarrojo cercano.

- Bandas correspondientes a dos descriptores de texturas de primer orden: Varianza y coeficiente de asimetría.

- Banda formada por el Î́ndice de Vegetación de Diferencia Normalizada (NDVI).

La selección de estas bandas se realizó mediante un análisis de separabilidad basado en la distancia estadística de Jeffries-Matusita, y el método de clasificación fue el de máxima probabilidad. Para la definición de muestras de aprendizaje sobre la imagen de 1999 se tomó como apoyo una imagen de alta resolución espacial (IKONOS, $1 \mathrm{~m} /$ píxel) adquirida en diciembre de 2000, mientras que para la de 1996 se creó la fusión de la imagen multiespectral del sensor LISS-III (24 m/píxel) con la imagen del sensor pancromático $(5.8 \mathrm{~m} / \mathrm{píxel})$, lo cual facilitó la interpretación e identificación de los distintos elementos presentes en la imagen.

La evaluación de la fiabilidad de las clasificaciones se realizó tomando muestras de evaluación sobre las imágenes de alta resolución descritas, mediante muestreo aleatorio estratificado, considerando cada clase como un estrato y seleccionando puntos de evaluación de forma aleatoria. De esta forma, se tomaron 200 puntos, cuarenta por cada clase. A partir de los valores obtenidos del muestreo se generaron las respectivas matrices de errores. La fiabilidad global obtenida en la clasificación de la imagen de 1996 fue del 80.5\%, mientras que en la de 1999 del 86\%. Además, las clases correspondientes al suelo residencial tuvieron una fiabilidad de usuario baja, del $65 \%$ en el caso de la imagen de 1996, y del $72.50 \%$ en la de 1999 . Esto quiere decir que de cada 100 píxeles clasificados como suelo residencial, tan sólo 65 y 72 
pertenecían realmente a esa clase, respectivamente. Ello implica un error por exceso de superficie clasificada como suelo residencial, que es precisamente una de las clases con mayor interés en clasificar correctamente. La generación de la imagen de cambios se obtuvo mediante operaciones de álgebra de imágenes.

\section{Método mixto de diferencia-clasificación}

Este método consiste en la obtención de una imagen diferencia entre la segunda banda de la imagen de 1996 y segunda banda de la imagen normalizada de 1999. De igual manera que en el caso del método del vector de cambios, no todos los valores de la banda diferencia suponen un cambio real, por lo que es preciso definir un valor umbral. Suponiendo que los extremos del histograma de la imagen diferencia recogen la información relativa a los cambios, se estudiaron dos umbrales de cambio que mejor se adaptaban al problema, $\mu \pm 1 \sigma$ y. $\mu \pm 2 \sigma$. A partir de estos umbrales se generaron máscaras de zonas de cambio, que fueron evaluadas eligiéndose finalmente el umbral de $2 \sigma$. La diferencia entre bandas no aporta información sobre el tipo de cambio, tan sólo registra dónde se produce. Para conocer el tipo de cambio, este método se basa en la superposición de la imagen diferencia sobre la clasificación de 1999, obteniendo una imagen de cambios con información local, cuantitativa y cualitativa de los mismos. Manteniendo sólo los cambios hacia suelo urbanizado se obtuvo la imagen de cambios de la figura 7 .

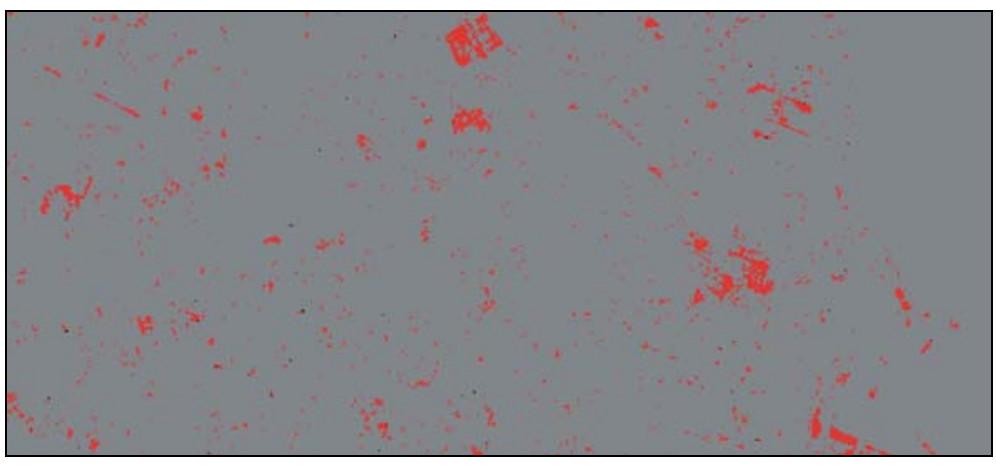

Cambios Urbanos Zonas sin cambios urbanos

Figura 7. Máscara de cambios obtenida mediante el método mixto de diferenciaclasificación.

Comparación y selección del método de detección de cambios

De los tres métodos analizados, vector de cambios, comparación postclasificación y diferenciaclasificación, el segundo se descartó a partir de un análisis preliminar, constatando una acumulación de los errores de las respectivas clasificaciones al combinarlas entre sí. La evaluación de los otros dos métodos se realizó a partir de la aplicación de un muestreo aleatorio de puntos sobre las dos imágenes, las cuales sólo presentaban dos clases, zonas de cambios urbanos y zonas sin cambio. Se seleccionaron 50 puntos de muestreo, 25 por clase. El valor de la clase de referencia para cada uno de estos puntos se determinó a partir de la imagen de alta resolución espacial IKONOS. A partir de los valores obtenidos se calculó la matriz de errores.

En ambos casos se obtuvo una fiabilidad global del 92\%. Mientras que en el método del vector de cambios se cometían errores por defecto en la detección de cambios urbanos (14\%), mediante el método mixto de diferencia-clasificación los errores eran por exceso (16\%), 
$\begin{array}{ll}\text { Architecture, City, and Environment } & \\ \text { Arquitectura, Ciudad y Entorno }\end{array}$

resultando en este caso un área total de zonas de cambio sobrestimada, tal y como se recoge en la tabla 1.

Tabla 1. Fiabilidades de la imagen clasificada. Métodos del vector de cambios y diferencia reforzado.

\begin{tabular}{|l|l|l|l|l|}
\cline { 2 - 5 } \multicolumn{1}{c|}{} & \multicolumn{2}{l|}{ Método del vector de cambios } & \multicolumn{2}{l|}{ Método diferencia-clasificación } \\
\hline Clase & $\begin{array}{l}\text { Error por } \\
\text { defecto }\end{array}$ & Error por exceso & $\begin{array}{l}\text { Error por } \\
\text { defecto }\end{array}$ & Error por exceso \\
\hline $\begin{array}{l}\text { Cambios } \\
\text { urbanos }\end{array}$ & $14 \%$ & $0 \%$ & $0 \%$ & $16 \%$ \\
\hline $\begin{array}{l}\text { Zonas sin } \\
\text { cambio }\end{array}$ & $0 \%$ & $16 \%$ & $14 \%$ & $0 \%$ \\
\hline
\end{tabular}

La superficie de cambios de suelo no urbanizado a urbanizado por el método del vector de cambios fue de $3.426 .624 \mathrm{~m}^{2}$, frente a los $3.810 .240 \mathrm{~m}^{2}$ que se obtuvieron mediante el método de diferencia reforzado. Se eligió el método del vector de cambios como más adecuado porque requería menos cálculos y porque no sobredimensionaba tanto la superficie de cambios urbanos. Una vez obtenidas las nuevas zonas de cambios se realizó su vectorización y edición, superponiéndola a la cartografía base (figura 8).

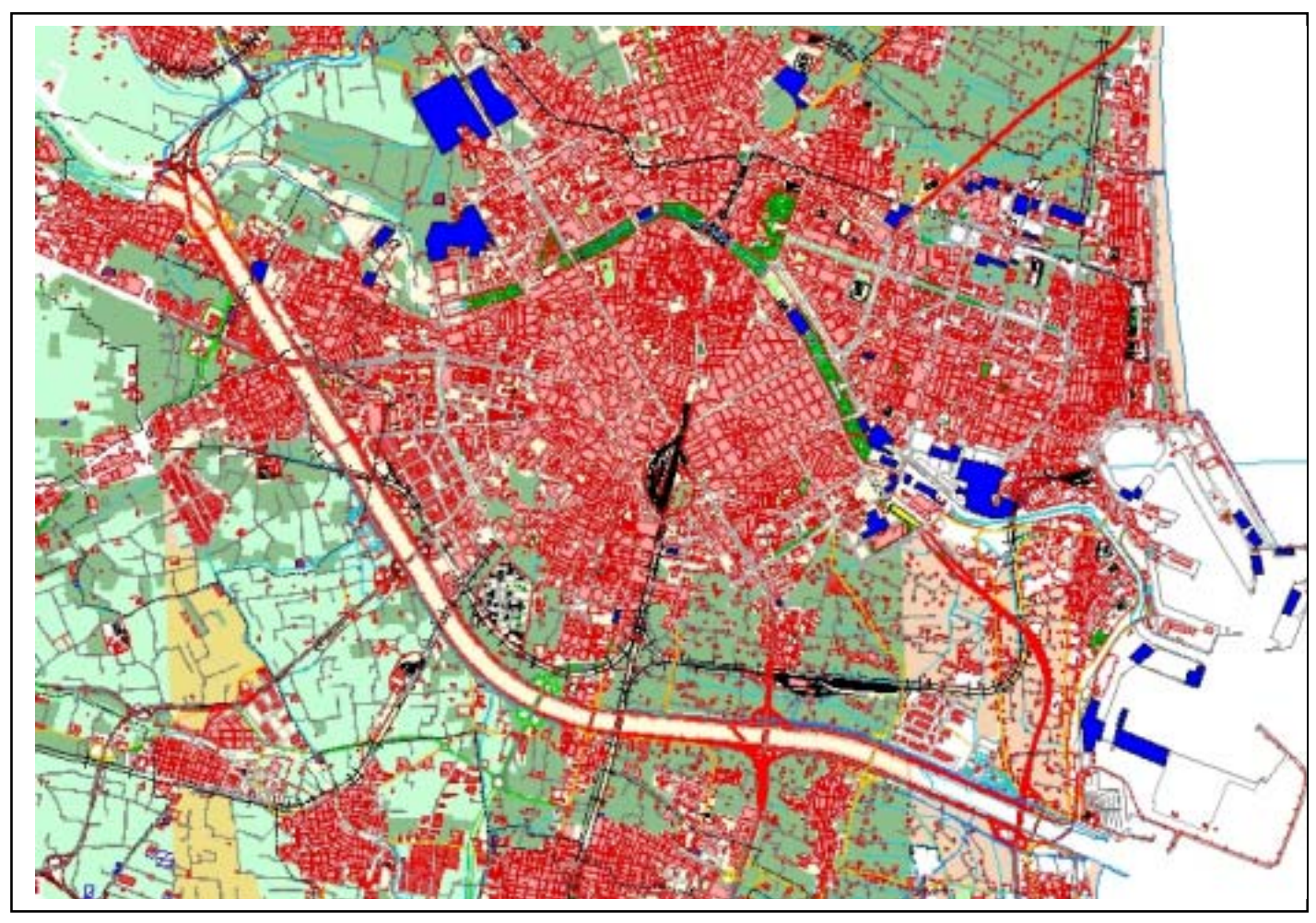

Figura 8.- Superposición de las zonas de cambio con la cartografía a escala 1:10.000. 


\section{Ortorrectificación de la imagen de alta resolución (QuickBird)}

La generación de una ortoimagen digital a partir de una imagen de satélite consiste en la corrección de las deformaciones geométricas debidas tanto al proceso de adquisición como al relieve del terreno, así como en la corrección radiométrica de las impurezas debidas a las saturaciones del sensor, y a las operaciones de realce de la imagen final. El producto final, por tanto, consiste en una imagen realzada que posee calidad y rigor cartográficos. El procedimiento seguido se muestra en la figura 9.

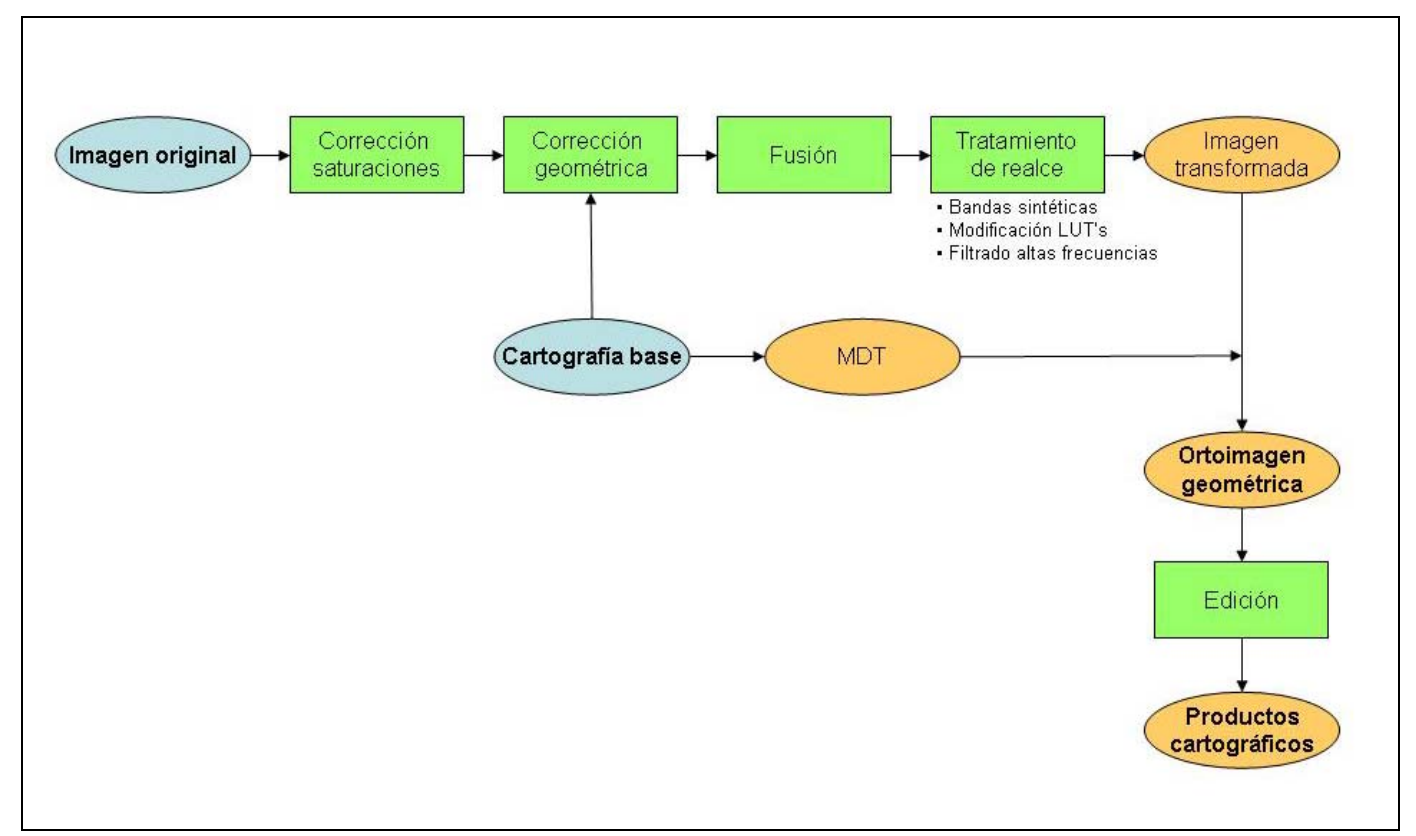

Figura 9.- Procedimiento del proceso de generación de la ortoimagen.

A continuación se describe la metodología seguida en la identificación y eliminación de saturaciones, la fusión de las imágenes pancromática y multiespectral, la generación de la ortoimagen geométrica, y las operaciones de realce y edición finales.

\section{Corrección de saturaciones}

Los sensores a bordo del satélite QuickBird poseen una elevada sensibilidad a la radiación, lo cual permite obtener imágenes de gran calidad y detalle espacial, pero también genera en ocasiones errores radiométricos causados por la saturación de los detectores debido a la gran reflectancia de ciertos objetos, generalmente metálicos (tejados de naves industriales, vehículos, etc. Cuando se trata de producir un producto final de calidad, estas saturaciones deben eliminarse y, en la medida de lo posible, el proceso de identificación y corrección deberá ser automático.

El procedimiento seguido consistió en definir las morfologías de error, establecer umbrales en el histograma de las imágenes y en la aplicación de una serie de filtros morfológicos y de suavizado. La figura 10 muestra los pasos del procedimiento seguido sobre un detalle de la imagen pancromática, donde puede apreciarse el destello provocado por la elevada reflectancia puntual del techo de un vehículo (10a). El modelo de corrección es el siguiente (Ruiz R. y Ruiz L.A., 2005): 
- Establecimiento de umbrales para determinar las zonas que han sufrido saturaciones. Estos umbrales deben ser dos, uno para determinar los elementos puntuales que han provocado la saturación del sensor, cuyo valor se estableció en 1800 (figura 10b). Otro umbral inferior para determinar las zonas de transición hasta que se estabiliza el sensor, cuyo valor fue determinado en 600 (10c).

- Dilatación morfológica de la imagen de umbral alto para delimitar las zonas de umbral bajo que han sido producidas por saturaciones del sensor. Este proceso consta de sucesivas dilataciones, primero en todas las direcciones y después sólo en la dirección de propagación de la saturación o avance del satélite, en este caso verticalmente (10d).

- Extracción, sobre la imagen de umbral bajo, de las zonas afectadas por el área generada tras el proceso de dilatación anterior (10e).

- Separación de la zona origen de la saturación (10f).

- Una vez separadas, las zonas origen y subsiguientes (colas de destello) se corrigen de diferente manera. La eliminación de las colas de destello subsiguientes se realiza aplicando un filtro de media a partir de los valores de su vecindario, excluyendo aquellos píxeles afectados. En cambio, en las zonas de origen, con una gran saturación, se aplica un filtro de suavizado de ventana $7 \times 7$ y con ponderaciones concéntricas, dándole al píxel central menos peso y a los extremos el máximo, como se muestra a continuación:

$\begin{array}{lllllll}1 & 1 & 1 & 1 & 1 & 1 & 1 \\ 1 & 0,7 & 0,7 & 0,7 & 0,7 & 0,7 & 1 \\ 1 & 0,7 & 0,3 & 0,3 & 0,3 & 0,7 & 1 \\ 1 & 0,7 & 0,3 & 0,1 & 0,3 & 0,7 & 1 \\ 1 & 0,7 & 0,3 & 0,3 & 0,3 & 0,7 & 1 \\ 1 & 0,7 & 0,7 & 0,7 & 0,7 & 0,7 & 1 \\ 1 & 1 & 1 & 1 & 1 & 1 & 1\end{array}$

Una vez aplicadas las correcciones obtenemos una imagen libre de saturaciones (figura $10 \mathrm{~g}$ ).
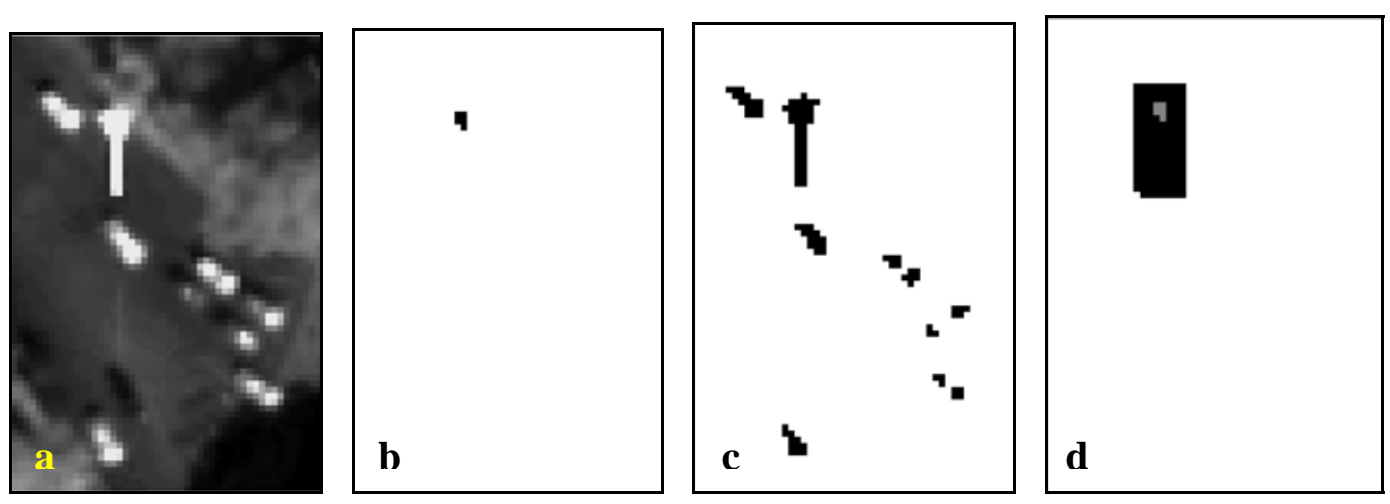

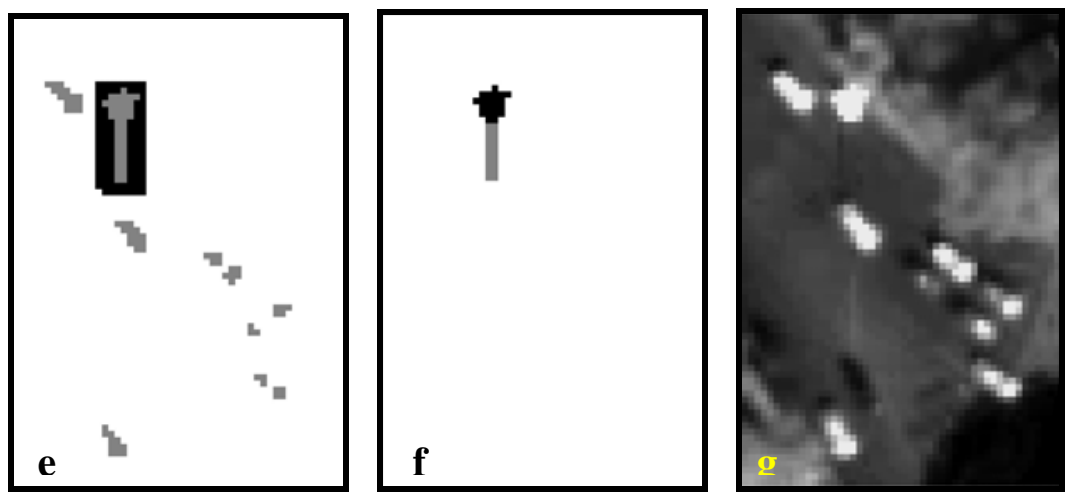

Figura 10.- Procedimiento de corrección de saturaciones: a) detalle de imagen original; g) imagen corregida.

\section{Fusión de imágenes}

El objetivo de la fusión de imágenes es combinar en una misma imagen la resolución espacial de la imagen pancromática con la información espectral de la imagen multiespectral. Antes del proceso de fusión se georreferenció la imagen pancromática y se registró la imagen multiespectral con respecto a ella.

Para rectificar y georreferenciar la imagen pancromática se utilizó la cartografía catastral urbana y la cartografía municipal comentada anteriormente. Se emplearon 274 puntos de control distribuidos homogéneamente en la zona de trabajo, aplicándose un ajuste polinomial de $2^{\circ}$ grado. El error medio cuadrático total obtenido mediante 36 puntos de evaluación fue de 0,934 píxeles. En el proceso de se emplearon 113 puntos de control y un procedimiento similar al anterior, obteniéndose un error medio cuadrático total de 0,494 píxeles, utilizando 18 puntos de evaluación.

En el proceso de fusión se ensayaron cuatro métodos diferentes: multiplicativo, Brovey, transformación al espacio HSI y transformación de componentes principales. La evaluación de la calidad espacial se realizó mediante análisis visual, mientras que la calidad espectral se valoró mediante la diferencia de medias y el coeficiente de correlación entre las bandas antes y después de la fusión, obteniendo los mejores resultados con el método basado en la transformación de componentes principales, por lo que la fusión definitiva se realizó empleando este método. La figura 11a muestra un detalle del resultado.

\section{Generación de la ortoimagen geométrica}

En la generación de la ortoimagen se hace uso de un modelo digital del terreno (MDT) para corregir las variaciones tridimensionales. La correspondencia entre el píxel imagen y su conjugado en el terreno se caracteriza por una condición de colinearidad. Esto se ha dispuesto mediante relación directa que consiste en proyectar el espacio imagen sobre la superficie objeto.

El MDT se generó a partir de la cartografía digital disponible de la serie 1:10.000 (hojas 696 y 722 de la serie L). A partir de los ficheros de curvas de nivel y puntos de cota, se obtuvo una red irregular de triángulos (TIN). Posteriormente, se corrigieron los errores y se convirtió en formato ráster (10 m/píxel).

El proceso consiste en aplicar una orientación interna, seguida de una orientación externa de la imagen. Antes de aplicar el proceso de orientación interna se obtuvieron las características ópticas del sensor QuickBird: distancia focal, tamaño del detector y el número de columnas del 
sensor. También se fijaron los parámetros del modelo. Estas características se pueden ver en la tabla 2.

Tabla 2.- Parámetros orientación interna

\begin{tabular}{llllll}
\hline INFORMACIÓN GENERAL & \multicolumn{4}{l}{ PARÁMETROS DEL MODELO } \\
\hline Distancia focal & $8836,202 \mathrm{~mm}$ & $\mathrm{X}$ & 2 & Omega & 0 \\
Tamaño detector & $0,0068 \mathrm{~mm}$ & $\mathrm{Y}$ & 2 & Phi & 0 \\
Columnas del sensor & 27552 & $\mathrm{Z}$ & 2 & Kappa & 2 \\
\hline
\end{tabular}

Para obtener la orientación externa se realizó una triangulación teniendo como referencia planimétrica la imagen pancromática rectificada y como referencia altimétrica el MDT generado. Se emplearon 30 puntos de control para la ortorrectificación y 7 puntos para evaluar la transformación. La tabla 3 muestra los parámetros de precisión de la triangulación.

Tabla 3.- Precisión de la triangulación

\begin{tabular}{lll}
\hline & CONTROL & EVALUACION \\
\hline Ground X $(m)$ & 0,1638 & - \\
Ground Y $(m)$ & 0,1889 & - \\
Ground Z (m) & 0,2931 & - \\
Imagen x (píxel) & 0,0026 & 0,3285 \\
Imagen y (píxel) & 0,0592 & 0,2299 \\
\hline
\end{tabular}

En el remuestreo final de la imagen se aplicó el método de interpolación bilineal, generando un píxel de salida interpolado de 0,60 $\mathrm{m}$.

\section{Tratamiento de realce}

Su objetivo es el de mejorar la apariencia visual de la imagen para facilitar la identificación de elementos y su interpretación. Consta de tres fases: (1) Creación de bandas sintéticas; (2) ajuste del histograma a partir de LUT's de color; y (3) filtrado de realce de las altas frecuencias

Con la creación de las bandas sintéticas se pretende mejorar la falta de contraste generada por el efecto de la dispersión atmosférica, que afecta más a las bandas de menor longitud de onda. Se creó una nueva banda verde a partir de la combinación lineal de las bandas verde e infrarroja, según la expresión: Verde' $=(4 \cdot$ verde + NIR $) / 5$. Por otra parte, la nueva banda azul se obtuvo directamente a partir de la verde original.

El objetivo del ajuste del histograma a partir de LUT's de color es mejorar el contraste y obtener un balance de color equilibrado. Por último, se realizó un filtrado de realce de altas frecuencias de $7 \times 7$ y con un valor del píxel central de 55. La figura 11 muestra, en un detalle de la imagen, los distintos pasos de realce realizados. 


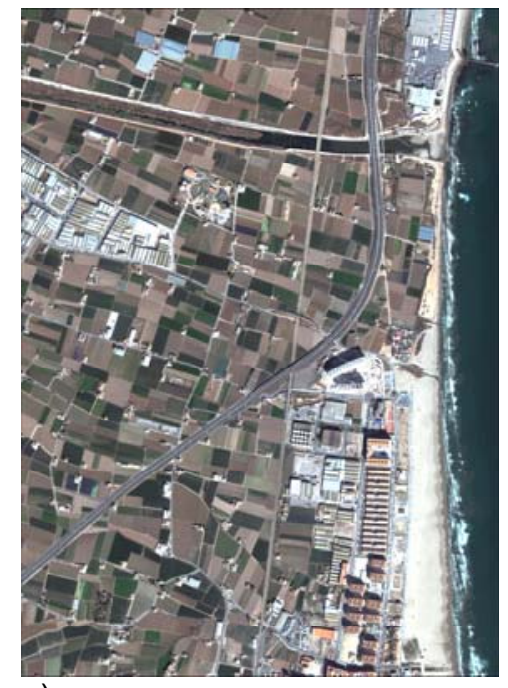

a)

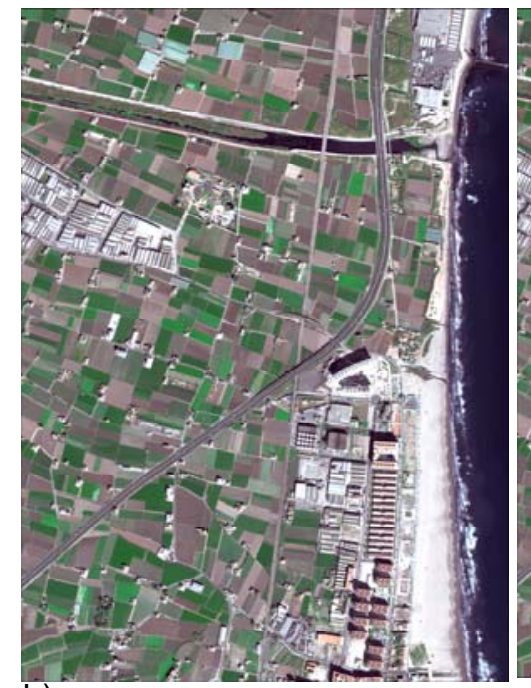

b)

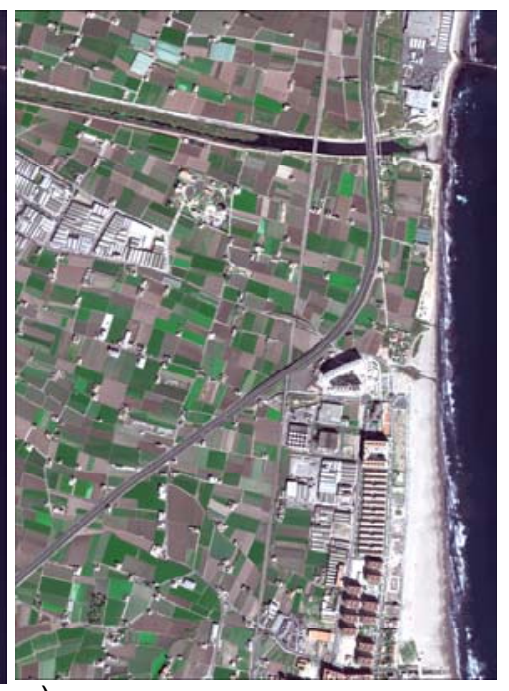

C)

Figura 11.- a) Resultado de la fusión mediante transformación de componentes principales; b) aplicación de las bandas sintéticas; c) imagen final tras el ajuste de histogramas y aplicación del filtro de realce de las altas frecuencias.

Además de la ortoimagen digital de Valencia se generaron, como productos paralelos, diversas ortoimágenes de los distritos administrativos de Valencia y de los municipios del área metropolitana. Para la edición se combinó una imagen pancromática remuestreada a 2,4 metros, como fondo, con la ortoimagen en color de 0,6 metros generada. En la maquetación se realizaron composiciones tanto horizontales como verticales, a diferentes escalas, superponiendo una malla que representa el sistema de referencia cartográfico UTM. Los bordes incluyen información marginal referente al mapa de situación, información general (sistema de referencia cartográfico, sistema de representación e información del sensor QuickBird) y un breve resumen de la metodología utilizada. Las figuras 12 y 13 muestran ejemplos de los productos finales.
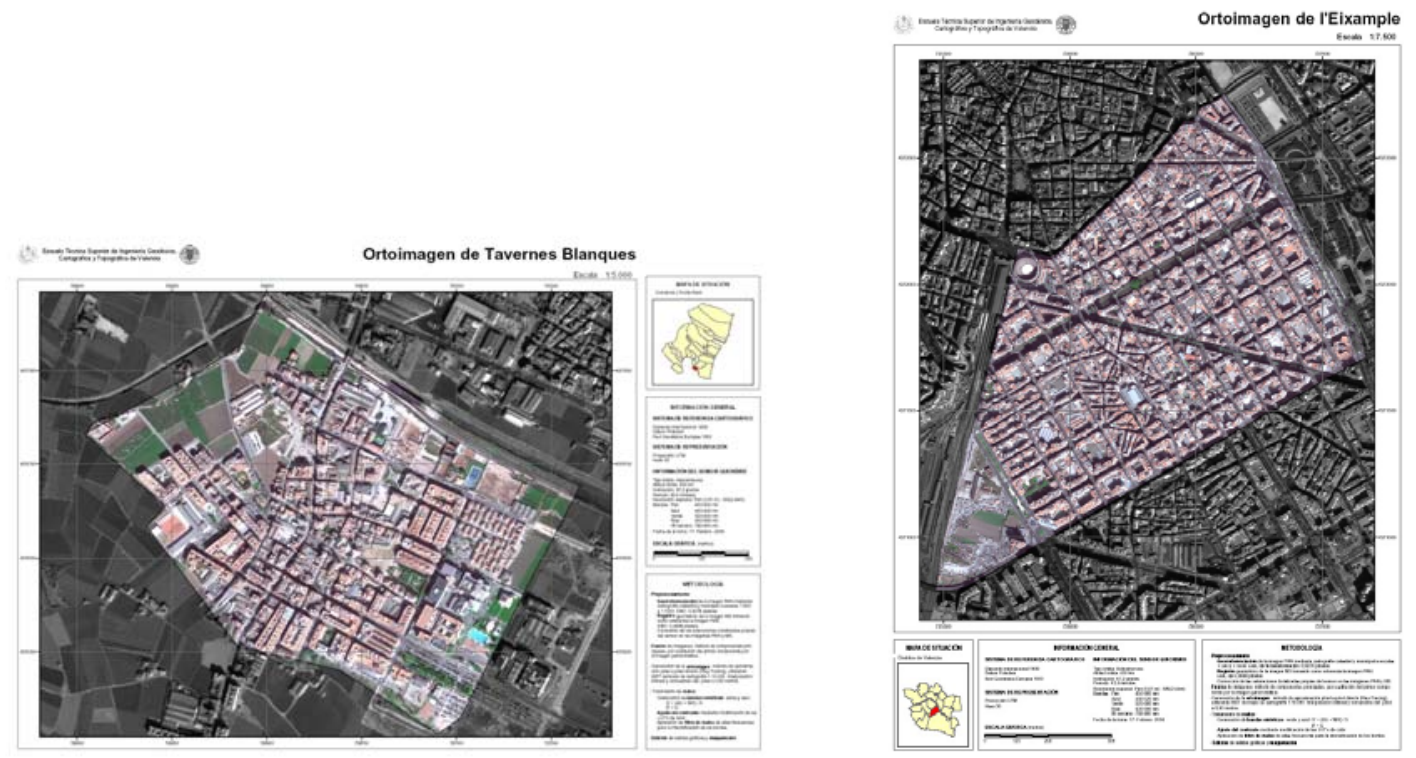

Figura 12. Ejemplos de las ortoimágenes maquetadas de municipios y distritos. 


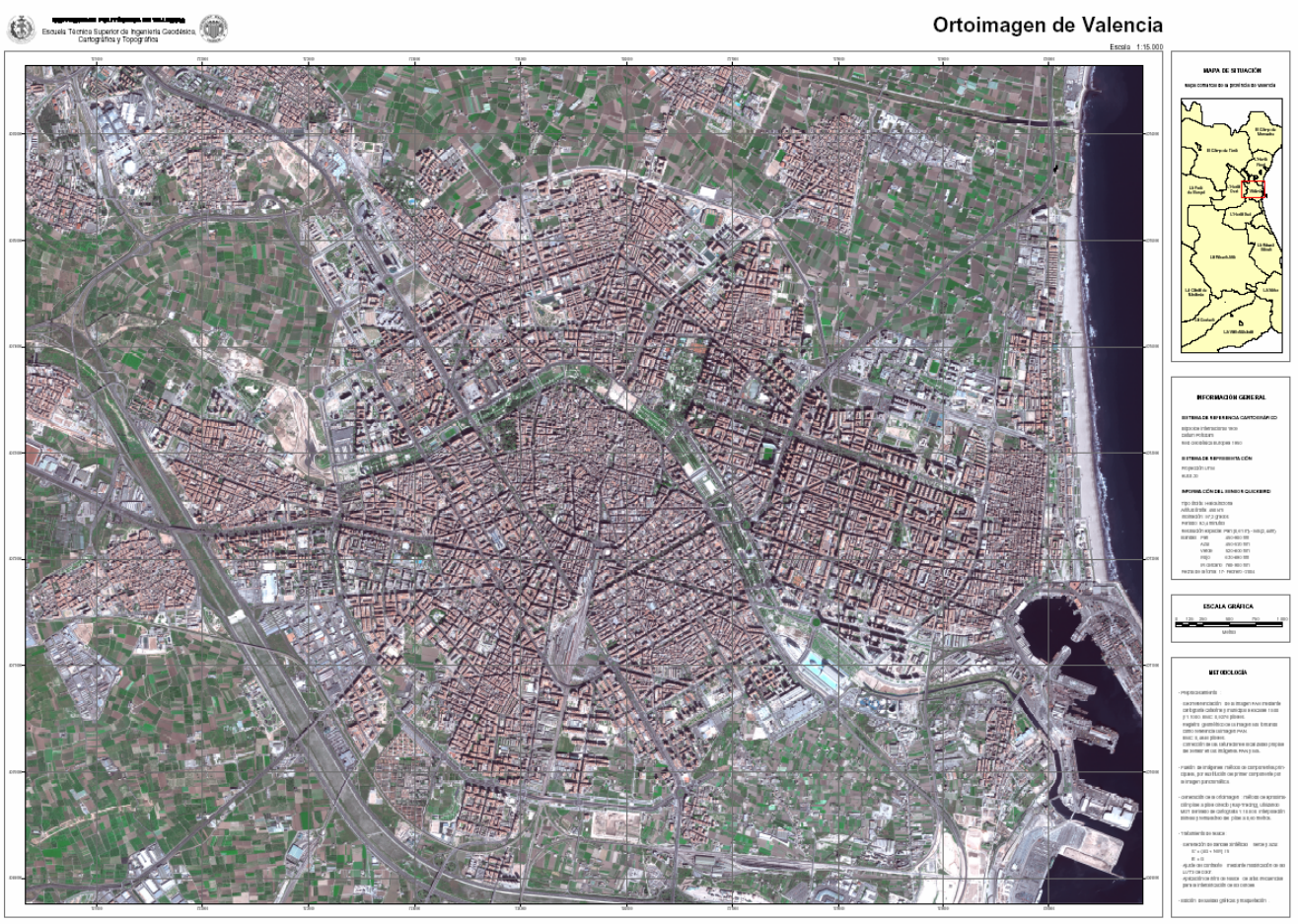

Figura 13.- Póster de Valencia y área metropolitana.

\section{Vuelo interactivo 3D}

Se generó un vuelo interactivo combinando la ortoimagen espacial de alta resolución y un MDT de 25 metros de resolución. Para la generación del escenario, al modelo 3D del terreno se le asoció la información referente a los cambios debidos al desarrollo urbanístico en la ciudad de Valencia entre los años 1996 y 1999, integrando los ficheros vectoriales obtenidos mediante el procedimiento de detección de cambios empleando técnicas de teledetección descrito en el apartado 3.

Los edificios de nueva construcción localizados en las zonas de cambios se levantaron volumétricamente a partir de la extrusión de la textura de la imagen y la especificación de la altura del edificio. Las zonas de cambio llevan asociada una base de datos SIG, lo cual permite la consulta de información referente a superficie y tipo de cambio, volumetría de edificios, etc., así como hiperenlaces a sitios web de interés.

Además, se diseñó una ruta (vuelo guiado) que permite al usuario observar el desarrollo urbanístico de la ciudad de Valencia desde una altura simulada de 250 m., conservando aún un cierto nivel de detalle en la visualización del terreno gracias a la elevada resolución espacial de la ortoimagen empleada. La figura 14 muestra una captura de pantalla de este vuelo. 


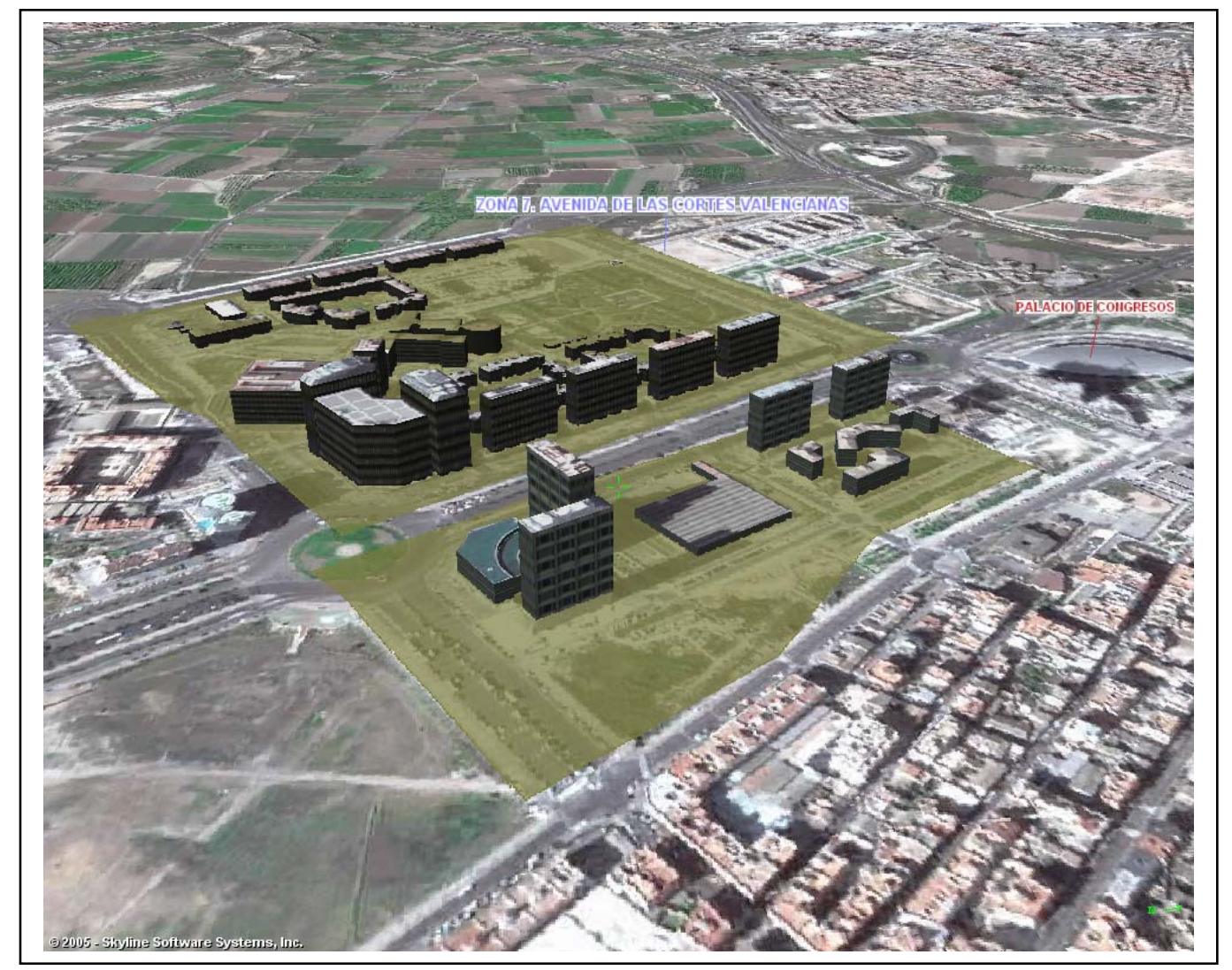

Figura 14.- Captura de pantalla de un detalle del vuelo 3D en el que se representan los cambios urbanísticos producidos.

\section{Conclusiones}

La metodología propuesta de detección de cambios en zonas urbanas mediante técnicas de teledetección permite automatizar gran parte de este tipo de procesos y trabajar a diferentes escalas en función de las características y necesidades de cada estudio. La evaluación muestra resultados satisfactorios en el caso analizado de la ciudad de Valencia utilizando imágenes de resolución media.

Las técnicas de procesado permiten obtener imágenes corregidas geométricamente con calidad cartográfica a partir de datos de satélite de alta resolución, con apoyo de la cartografía urbana disponible. Estas imágenes, combinadas con MDT, son útiles para la generación de espacios virtuales como vuelos 3D, sobre los cuales se puede incluir la información obtenida a partir del análisis de cambios. Todo ello supone la posibilidad de integrar procedimientos y datos con el fin de facilitar la gestión del territorio, en particular de los espacios urbanos que experimentan un importante crecimiento y donde se requieren estudios evolutivos de forma periódica. 


\section{Referencias bibliográficas}

ESTORNELL, J., RUIZ, L.A., PÉREZ, P., DEL REY, A., 2004. Análisis metodológico para la detección de cambios urbanos en la ciudad de Valencia. Revista de Teledetección (ISSN: 1133-0953). Asociación Española de Teledetección (AET). Vol. 22, pp. 55-66.

HOWARTH, P.J. and BOASSON, E. 1983. Landsat Digital Enhancements for Change Detection in Urban Environments. Remote Sensing of Environment. 13, 4: 291-300.

MATEU SÁNCHEZ, A y RUIZ FERNÁNDEZ, L.A. 1999. Comparación y evaluación de métodos de normalización radiométrica relativa. Revista de Teledetección. 12, 99-103.

MARTIN L.R.G and HOWARTH, P.J. 1989. Change-detection accuracy assessment using SPOT multispectral imagery of the rural-urban fringe. Remote Sensing of Environment. 30, 1: $55-66$.

RIDD, M.K. and LIU, J. 1998. A Comparison of Four Algorithms for Change Detection in an Urban Environment. Remote Sensing of Environment. 63, 2: 95-100.

RUIZ MARÍN, R., RUIZ FERNÁNDEZ, L.A., 2005. Generación de una ortoimagen digital a partir de un sensor espacial de alta resolución (QuickBird). Mapping (ISSN: 1131-9100). № 105 (pp. 52-56).

SOHL, T. L. 1999. Change Analysis in the United Arab Emirates. An Investigation of Techniques. Photogrammetric Engineering \& Remote Sensing. 65, 4: 475 - 484.

XIAOJUN, Y., LO, C.P. 2000.Relative Radiometric Normalization Performance for Change Detection from Multi-Date Satellite Images. Photogrammetric Engineering \& Remote Sensing. $66,8,967-980$.

YUAN, D., ELDVIDGE, C.D., 1996. Comparison of relative radiometric normalization techniques. ISPRS J. Photogramm. Remote Sensing. 51, 117 - 126. 
